\title{
MicroscopyPioneers
}

\section{Pioneers in Optics: Heinrich Rudolph Hertz}

\section{Eric Clark}

From the website Molecular Expressions created by the late Michael Davidson and now maintained by Eric Clark National Magnetic Field Laboratory, Florida State University, Tallahassee, FL 32306

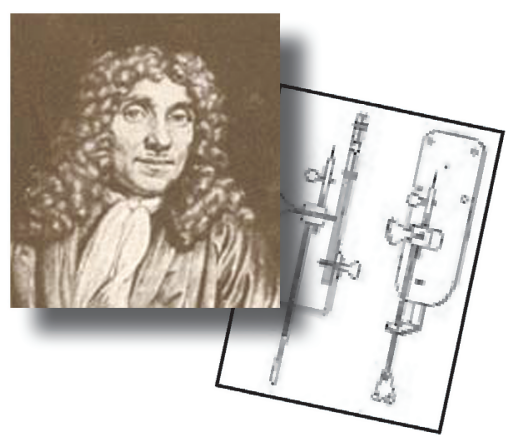

eclark@magnet.fsu.edu

\section{Heinrich Rudolph Hertz (1857-1894)}

The German physicist Heinrich Hertz is widely known for being one of the first scientists to broadcast and receive electromagnetic waves, but he is also important for his contributions to the field of optics. Most notably, Hertz was the first investigator ever to observe the phenomenon that would eventually come to be known as the photoelectric effect. The discovery of this phenomenon, which is generally defined as the emission of electrons

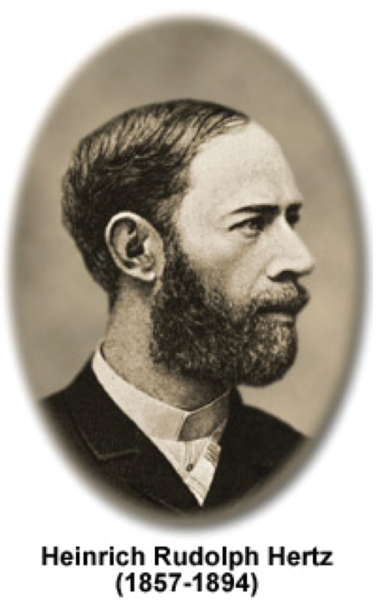
from a surface exposed to electromagnetic radiation above a certain threshold frequency, had a tremendous influence on the perception of light, which was just beginning to be understood in terms of a duality between waves and particles late in Hertz's lifetime, and which would not come to be widely accepted until many years after his death.

Heinrich Hertz was born on February 22, 1857, in Hamburg, Germany, but studied in a number of different cities, including Dresden, Munich, and Berlin, under a number of prestigious scientists, such as Hermann von Helmholtz and Gustav Kirchhoff. Hemholtz reportedly had a particularly strong influence on the young scientist, who would continue to study with him for several years after he received his doctorate degree magna cum laude in 1880. In 1883, however, Hertz accepted a position as lecturer of theoretical physics at the University of Kiel. He was appointed as a full professor at the Karlsruhe Polytechnic in 1885, a post he retained until 1889, when he became a professor of physics at the University of Bonn. It was at Karlsruhe that Hertz carried out many of his most important experiments.

In the late $1800 \mathrm{~s}$, a number of physicists attempted to detect and generate electromagnetic waves in order to prove James Clerk Maxwell's theory of electromagnetism, which was published in 1865 . The first to actually accomplish this feat was Heinrich Hertz, who constructed an oscillator formed from brass knobs. Each of the knobs was connected to a highvoltage induction coil and was separated from the other knob by a small gap, over which sparks could travel. If Maxwell's theory was correct, Hertz postulated, when a spark created a conducting path between the brass knobs, electromagnetic radiation would be emitted as charge rapidly vacillating back and forth between them. To detect the radiation Hertz built a simple receiver from copper wire with a brass knob located at one end, and the other end formed into a point. The wire was bent into a circle so that the knob was very close to, but not touching, the pointed end of the wire. The design enabled the presence of charge to be detected through the observation of a spark crossing the gap between the knob and point. Using these basic instruments, Hertz was able to clearly demonstrate that electromagnetic waves did exist and that they travel, as suggested by Maxwell, at the speed of light.

In the course of his experiments with electromagnetic radiation, Hertz did encounter some problems, primarily involving the detection of the small spark produced in the receiver. To aid in the visibility of the spark, he sometimes enclosed the receiver in a dark case, which he observed had an unusual effect on the maximum length of the spark, making it smaller than when no case was used. His findings led him to more thoroughly investigate the matter, resulting in his determination that the spark produced was stronger if it was exposed to ultraviolet light. Though he offered no explanation for this puzzling matter, other scientists recognized the import of the discovery, and, by 1899, J. J. Thomson ascertained that the ultraviolet light caused the emission of electrons, hence the more vigorous spark. This phenomenon, which was later dubbed the photoelectric effect, is central to the understanding of modern physics.

Although his contributions to science were significant, Heinrich Hertz would likely have had an even more fruitful career if his life had not ended prematurely. At the age of 37 , the eminent scientist, who made great scientific leaps while maintaining his characteristic modesty, died of blood poisoning. He was survived by his wife, Elizabeth, and two daughters. The common unit of frequency, Hertz $(\mathrm{Hz}$; cycles per second), was named in his honor and became officially included in the metric system in 1933. 

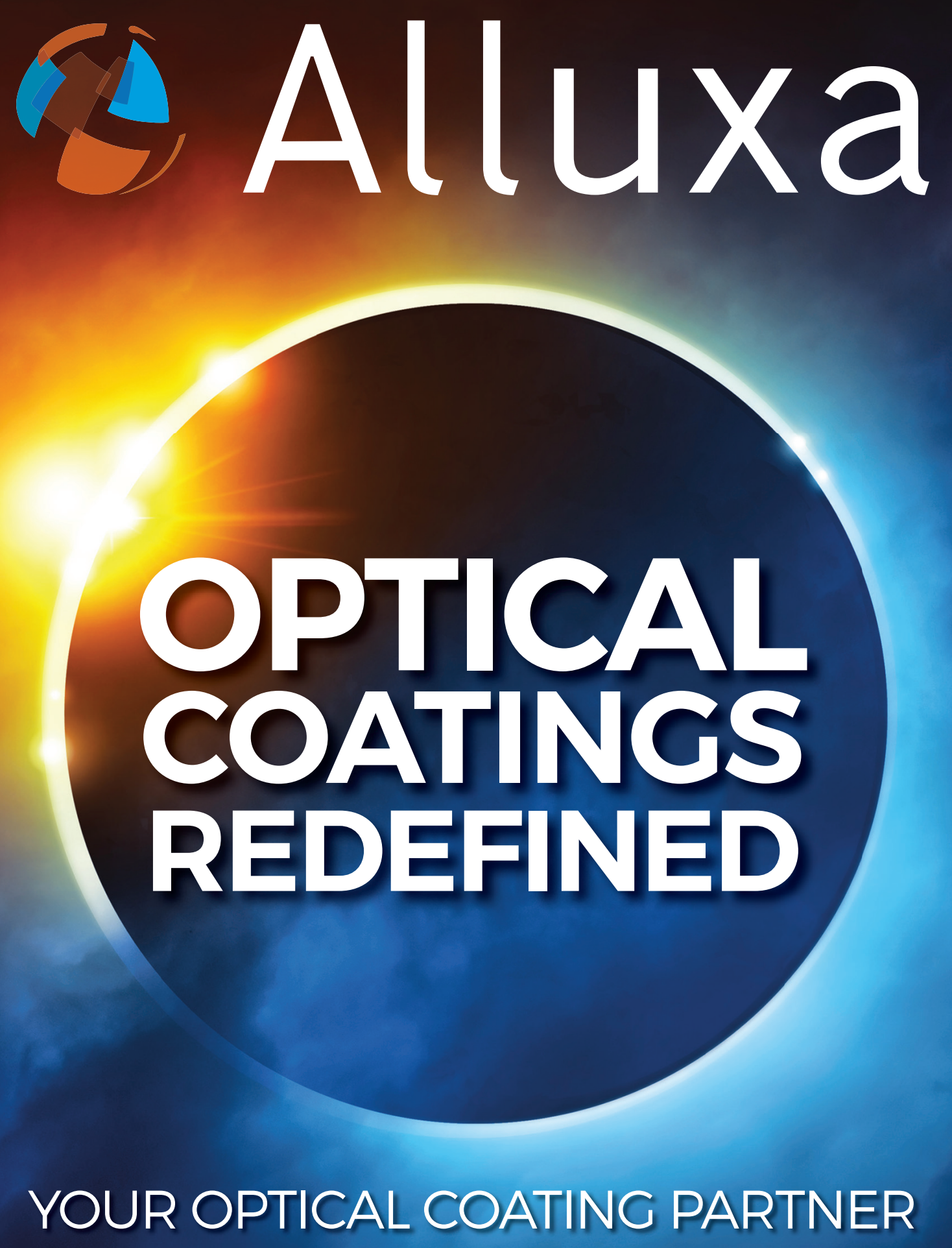

\section{SPIE PHOTONICS}

FEBRUARY 5-7, 2019

BOOTH \#4482 NORTH HALL 